\title{
Historical experience of the Soviet period Russian school in the context of information society development
}

\author{
Galina N. Kozlova ${ }^{1}$, Anatolii V. Ovchinnikov, ${ }^{2, *}$ \\ ${ }^{1}$ Minin NNSPU, Theoretical Foundations of Physical Culture Department, Nizhny Novgorod, Russia \\ ${ }^{2}$ ISED RAE, Laboratory of History of Pedagogy and Education, 105062, Moscow, Russia
}

\begin{abstract}
The process and basic tendencies of creating scientific information related to the development of the Russian comprehensive school during the Soviet period are considered in the paper. The conclusions and generalizations are based on the analysis of articles and dissertation papers published in Russia in Soviet and post-Soviet time
\end{abstract}

As a result of the multidisciplinary analysis of the current social development processes reflected in classic papers by D. Bell, Z. Brzeziński, A. Toffler and other researchers, the development issues of mankind and culture in conditions of information society have acquired a special significance. They have rightly deserved a leading position among the scientific research rating in the field of economics, social philosophy, political and, of course, education sciences.

In these circumstances the providing of vision on general historical process of the domestic education development, adequate to modern science and social objectives becomes an important methodological task. This is especially true for the period of its modernization and development under Soviet society conditions, which has by now become an important and debatable phase of the Russian civilization development. It was during this period that the information space of our country significantly changed and expanded, in which the education system has played not the last role. "The efficiency of information society as a knowledge-based social system presupposes a high level of rational organisation, mutual understanding, coordinated and harmonised cooperation" [1]. This A.I. Rakitov's statement is still of great methodological importance.

It is socio-political conditions like these that were present throughout the Soviet period of Russian education development, it especially concerns the final stage. It is also specific that the mentioned paper, published more than 20 years ago, is still being referred to by many researchers.

From the first years of the Soviet regime the information and communication space of Russia completely changed its character as compared to the previous period. This development revealed itself in the two aspects: first, in creating a totally different education system as well as its information and propagandistic coverage, and later in its historiographic discourse reflecting this process. The latter fact is especially important, because it is this information that provided grounds for the present-day ideas of the Russian comprehensive school during the Soviet period, and, correspondingly, the basis for making a decision on its applicability in the present context.

At the end of $20^{\text {th }}$ - beginning of $21^{\text {st }}$ century there was a fundamental turn in the humanities, which coincided with notable changes in understanding and interpretation of historical experience of the Soviet education system. New meanings were given to methodological and historiographic issues, related to, above all, historic determinacy of education system development and adequacy of Soviet school policy. There was a need to rethink earlier assessments of school education reforming processes.

It was noted that disregard of crises of the Soviet school that was amplified the 1980-s, led to grave problems in the Russian education system, which later negatively affected the development of Russian education as an important component of information society.

In this regard it should be noted, that those years were the time of the maximum imbalance between the insufficient informational and educational milieus, which in fact existed to realize the educational potential of Soviet people, and the goals of balanced and harmonized personality development, declared by the Soviet government. This does not refer to the quality of education, which all in all met the needs of society. The Soviet education and its students lacked a informational environment, which could objectively highlight all the strengths and weaknesses of the Soviet school development, which were characteristic of it throughout the Soviet period of history.

Humanitarian researchers take a considerable interest in the history of the Soviet school, which virtually reform our ideas of Soviet education system development during this unique social experiment involving millions and several generations of people. Its vastness itself was a factor to expand the information 
field raising an issue for serious scientific and political discourse on manifold socio-educational problems, for which no solution expertise was available by that time.

It is enough to mention the fact that during the first months of the new regime in Russia the education reforming activities drastically changed the country's information space and filled it with new and earlier unknown meanings. Successful implementation of those ideas required a lot of effort and will of the new government, which needed a new information environment, adequate to the new political objectives. The discussion of people's education within and between various social groups, which was painfully emerging during the post-reforming period, was replaced first by mono-ideological discourse of the ways of Soviet education development, and after that by a categorical policy, which of course affected the educational and informational space of the Soviet society as well.

Special importance was attached to the information on the ways, prospects, forms and methods of creating a new education system in different regions of the multinational Russian Federation. Russian education media space was filled to the top by organisational, pedagogical and innovation content in that time. There was lack of interest in centuries-old traditions of Russian school, which along with the national culture was planned to be "thrown overboard from the ship of modernity" (Translator's note: The quote is from A Slap in the Face of Public Taste, Russian Futurist manifesto, 1912). The primary focus of information flows focused on the mass user was given to the People's Commissariat of Education and its divisions: Glavsotsvos (Central Agency for Social Education) and others. The information policy of the new state attached special importance to propaganda of general education, which later became the main direction, which determined the development of Russian education information space for decades.

The information space of education became an area of serious ideological work aimed to breed the new Soviet person. At the same time a lot of attention was paid to organizational matters. School planning and Soviet education budgeting issues were continuously updated. Statistical accounting and its use for working out optimal school policies had become a traditional line of work dating back to pre-revolutionary times.

The problem of universal education emerged in prerevolutionary times too, playing an important role in Soviet education information space, but it required a totally new ideological interpretation.

Thus, during the first decade of the Soviet regime the government managed to create a new informational and communicational educational space, which was generally capable of achieving the political goals.

In the late 1920-s - late 1930-s the character of information activities of the Soviet government in the field of education was changed due to a total change in the political course. Under these conditions new goals were set for the education system which had reached a mono-state status. It was during those years that the tendency towards positive school building achievements informing was strengthening. The Soviet public focused attention on the positive achievements of Soviet school. Complete positive and world-scale achievements amid aggravating class struggle - that was the informational burden of the Soviet government in respect to school development in the country. It was thanks to the elaborate system of informational activities the ideal image of the domestic general education with a touch of positive mythological grounds has been formed.

The information space of Russian education in 1930$\mathrm{s}$ was filled with new ideas, which began to get implemented in the context of altered school policies. Not only specialized pedagogical editions, but also general mass-media started paying to pedagogical issues, others than earlier. For instance, pedagogical and parental society started taking interest in issues related to school education efficiency analysis, lesson organization matters, educational material planning, polytechnic and professional training.

Speaking about the pre-war stage of information space development of the general education system in Russia, it should be noted that it was formed almost anew during this period. It was due to a totally new legal framework of Russian education, implementation of the unified labor polytechnic school principle and creating a new type of pedagogue.

However, the tendency to oppose the prerevolutionary and post-revolutionary stages of comprehensive school forming stood in the way of creating an objective image of historical development of the Russian school.

With the end of World War II, especially from mid1950-s a new stage of Soviet education information space began, which was to great extent caused by a change in the country's political climate and so-called Ottepel ("The Thaw").

Russian education information space of those times was characterised by expanded, though limited, use of foreign experience and dosed amount of criticism of the Soviet education system. For example, it was allowed to openly express criticism towards some forms of primary and later seven-year schooling in the USSR. New data on local dissatisfaction with school policy implementation in certain republics started to emerge.

The development of media, television and radio communication tangibly enriched the country's information space. The TV started performing an important educational and political function, largely contributing to knowledge expansion and unity of the Soviet educational space.

Starting from late 1960 -s - early 1970 -s we may speak of a new stage of information society development in the USSR. Education history scholars respectively changed their approaches to studying the schooling experience of the first Soviet regime years. This acquired great socially importance. It was during that period that the generation, who witnessed that epoch began passing away. Archives, memoirs, scientific and journalistic papers became the main source of information.

And it was in those times that the historic and Communist party issues started dominating the scientific and information space. In those papers main focus was put on the leading role of the Communist party in school development. As a positive example it should be noted that this period a nascent trend toward integration of social sciences was noticed. School education scholars, 
working with the historical context much more than pedagogy historians, involved knowledge from related areas thus increasing the informational value of their papers.

Information source expansion was a trend in the 1980 -s as well. It was during this period that thanks to political decision, the beginning of the Perestroika processes and expansion of freedom of speech, that the Russian historical space expanded to its maximum width, including the space of Russian education history.

This tendency coincided with a start of mass introduction of informational and communicational technologies, which contributed to the expansion of the range of historic research, simplified access to information, which could be used to reconstruct the complex and arguable processes of Russian education during its different development stages.

Earlier known materials were re-thought in publications of that time. New facts, acquired also due to expanded access to archives, were included in the studies of pedagogic history with significant carefulness, which was due to a long period required to re-think the dogmas and stereotypes built up during decades. It was also the ambiguousness of those times. While education historians were reconsidering the experience of the Soviet past, the information realm faced with a number of "sensational" denunciations which blew up the information space a number of times. Many authors reproached professional historians with being biased and following double standards. Although the history is gradually aligns all behind a direction, but the unpleasant aftertaste of these pseudo-disclosures engenders many doubts already in the second generation of Russian pedagogues and educators.

At the turn of $20^{\text {th }}-21^{\text {st }}$ centuries the information boom started stabilising to some extent, as in its grounds it was caused by different interpretations of the past of Russian schooling and education. The same trend is observed in respect to the history of Russian education system during World War II, the information space of which expanded to some extent during the celebration of the 70th anniversary of the Great Victory. Nevertheless, despite the enormous aggregation of historical sources gathered by now, this problem has still no adequate representation in the modern Russia's historical and pedagogical space.

Post-war years became an important landmark in expanding the information space of Russian education history. In spite of political and ideological bias, the literature and periodicals of those times were a rich source of information. Let us put forward an idea, that those years were to some extent a reiteration of the 1920$\mathrm{s}$ information experience, but under new monoideological conditions. Best pedagogical expertise was promoted as well. But it was strictly measured out by the Communist party control bodies.

In these years the awareness of wide public about the ways of the pedagogical science development was intensified. The importance of its influence on the improvement of the country's entire education system was stressed. The information space was filled with new meanings and ideas, which were developed due to a new ideological line of the Communist party and the Soviet government.

The 1950-s are notable for another feature. It was during that time that, of course, under the dominating system, a growing interest in legal methods of educational regulation was spotted. The role of legal information and enlightenment was growing. This tendency was characteristic of all the next years of soviet schooling.

Growing attention to general and specific issues of schooling science and teaching personnel instruction became an important area of Russian education information space development. In these years the ideas related to school management renovation methods, expansion of basis of democracy in school life, such as election of directors were frequently beginning to be sounded.

The information base of regional education bodies continued developing in those years. The information flow of advanced practices in pedagogy, daily school life and other educational institutions had significantly grown. The information space became richer, more interesting and informative.

For the 1980-1990-s information space it was typical to provide a great amount of information related to forms and methods of Russian school and social development of pedagogical teams. The trend of writing generalizing works, which was attended by big scientific teams becomes stable. It is, however, worth mentioning, that the class approach to the school life evaluation had been dominating the information space and stood in the way of objective coverage of the country's educational processes.

To sum up, it should be noted that studying the information space of education of Soviet Russia helps to reveal a few basic tendencies in scientific knowledge development in this area.

First, today it is important as never before to analyse the historic experience of Soviet school in the context of information society development, because it was during that times that its grounds were laid. Let us note that this issue has not been yet analysed in detail based on the latest achievements of the history and the history of pedagogy.

Second, careful attention should be paid to the fact, that insufficient methodological culture of contemporary researchers may become a significant problem in the historical and pedagogical substantiation of this issue. Particularly, this is revealed in the general loss of culture related to work with historical sources, especially those of the history of the Soviet period.

Third, due to underestimation of high-quality and scrupulous historiographic analysis of Soviet education development issues, the author's idea of a certain issue may gradually reduce into misunderstanding and ignoring what was earlier explained by preceding generationsof scientists. Under ever-growing amount of knowledge this factor may promote the formation of an irrational view of the past, which, under booming information society development, is being enriched with manifold historical implications. The genuine essence of these meaning, ever-growing in the information space, 
can be understood and realised only with the use of justified value and methodological positions. It is also important to keep the balance between philosophical reflexion and comprehensive interpretation of historical sources.

\section{Reference}

1. A.I. Rakitov, Philosophy of Computer Revolution (1991) [In Rus] 